\title{
Evidence of Association between Smoking and $\alpha 7$ Nicotinic Receptor Subunit Gene in Schizophrenia Patients
}

\author{
Vincenzo De Luca', Albert HC Wong', Daniel J Muller', Gregory WH Wong', Rachel F Tyndale ${ }^{2}$ and \\ James L Kennedy*, I \\ 'Neurogenetics Section, Clarke Site, Centre for Addiction and Mental Health, Department of Psychiatry, Toronto, Ontario, Canada; \\ ${ }^{2}$ Department of Pharmacology, University of Toronto, Toronto, Ontario, Canada
}

\begin{abstract}
A number of studies have suggested that the $\alpha$-7-nicotinic receptor DI5SI360 polymorphism is associated with schizophrenia and a deficiency in the normal inhibition of the P50 auditory-evoked response. Schizophrenia patients and some of their unaffected relatives show a failure of inhibition in their 50-ms response to the second of a pair of tones. Biochemical studies have suggested that the $\alpha 7$ nicotinic acetylcholine receptor is involved in this sensory gating deficit. Furthermore, high-dose nicotine transiently normalizes the abnormality in P50 inhibition in schizophrenic patients and in their relatives. Schizophrenic patients are unusually heavy smokers, and up to $85 \%$ of hospitalized schizophrenic patients smoke. This rate is three times higher than the general population, and may represent an attempt to self-medicate through this pathophysiologic mechanism. Despite schizophrenics' extremely heavy nicotine use, nicotinic receptor genes have not been previously investigated in relation to smoking in schizophrenia. In this study, we hypothesized that the DI5S I 360 marker is associated with smoking in patients with schizophrenia. We found an association between the homozygous II 3 bp allele and smoking risk $\left(\chi^{2}=10.37,3 \mathrm{df}, p=0.015\right)$. Although this novel finding requires replication, it suggests that further study into the relationship between schizophrenia and nicotine system genes is warranted.

Neuropsychopharmacology (2004) 29, I522-1526, advance online publication, 2 I April 2004; doi: I0.I038/sj.npp. 1300466
\end{abstract}

Keywords: CHRNA7; nicotine; smoking; schizophrenia; P50; sensory processing; auditory gating; addiction

\section{INTRODUCTION}

The incidence of cigarette smoking in psychiatric patients is approximately $40 \%$, but in schizophrenia it is much higher, approaching $80 \%$ (Leonard and Bertrand, 2001), and the amount that schizophrenic patients smoke is also higher (de Leon et al, 1995). It has been suggested that smoking may be an attempt by schizophrenia patients to self-medicate (Adler et al, 1998), and various studies have explored the possible links between schizophrenia and smoking. Patients with schizophrenia have abnormal P50 responses (Freedman et al, 1994) and nicotine transiently normalizes the P50 auditory evoked-potential deficit in both humans and animals (Adler et al, 1992, 1993; Leonard et al, 1996). Genetic linkage analysis of the P50 auditory-evoked potential deficit in families of patients with schizophrenia found a peak LOD score at 15q13-q14. The LOD score was 5.3 (theta $=0.00$ ) at the D15S1360 marker, which is located in intron 2 of the gene for the $\alpha 7$ nicotinic acetylcholine

\footnotetext{
* Correspondence: Dr JL Kennedy, Neurogenetics Sections, Clarke Site, Centre for Addiction and Mental Health, 250 College Street, R-30, Toronto, Ontario, Canada M5T IR8. Tel: + 416979 4987, Fax: + 416979 4666, E-mail: James_Kennedy@camh.net

Received 4 September 2003; revised 8 March 2004; accepted 15 March 2004

Online publication: 22 March 2004 at http://www.acnp.org/citations/ Npp03220403407/default.pdf
}

receptor subunit (CHRNA7), suggesting that the P50 deficit is linked to CHRNA7 (Freedman et al, 1997).

The CHRNA7 gene modulates evoked potentials in an auditory gating pathway in the rat (Adler et al, 1992; LuntzLeybhan et al, 1992). A mouse model has been developed in which a similar inhibitory sensory gating is also correlated with the CHRNA7 expression. Mice with a knockdown for CHRNA7 (DBA/2j) show disinhibited sensory gating compared to the $\mathrm{C} 3 \mathrm{H}$ mouse strain, which has normal levels of CHRNA7 mRNA. In addition, GTS-21, a specific agonist of $\alpha 7$ neuronal nicotinic receptors, normalizes this loss of inhibition in the DBA/2j strain (Stevens et al, 1996, 1998).

The nicotinic receptor containing the $\alpha 7$ subunit in human brain is assembled with other subunits as a pentameric holoreceptor (Lindstrom et al, 1996), but can function as a homomeric ion channel in vitro (Zhang et al, 1994). It belongs to the family of ligand-gated ion channels that bind nicotine with low affinity.

The CHRNA7 gene is located on chromosome 15q13-14, a region linked with schizophrenia in several earlier studies (Kauffman et al, 1998; Leonard et al, 1998). The $\alpha 7$ nicotinic receptor gene (CHRNA7) has a partial duplication of exons 5-10, including the intervening introns (CHRFAM7) that map approximately $0.5 \mathrm{Mb}$ proximal to the full-length CHRNA7 gene (Gault et al, 1998).

The $\alpha 7$ nicotinic receptor is expressed at low levels in schizophrenia postmortem brain. Regions of lower 
expression compared to psychiatric controls include those involved in processing of sensory information, such as the hippocampus and the reticular nucleus of the thalamus (Freedman et al, 1995; Court et al, 1999).

The D15S1360 microsatellite repeats, in intron two of the CHRNA7 gene, cosegregates with an auditory gating deficit in family linkage studies of schizophrenic patients (Freedman et al, 1997). This marker lies 33531 bp downstream relative to the end of exon 2.

Mutation screening of CHRNA7 from schizophrenia and control individuals identified promoter polymorphisms associated with schizophrenia that decreased the subunit transcription and P50 inhibition (Leonard et al, 2002). Recently, Gault et al (2003) described new SNPs in the alpha7 nicotinic receptor subunit gene; however, in contrast to D15S1360, they are not related to P50 deficit. Since these variants are rare and thus uninformative in currently available samples, we chose to genotype the D15S1360 marker, which has common variants, and is not duplicated, making the result easier to interpret in this unstable genomic region.

\section{PATIENTS AND METHODS}

We recruited 177 schizophrenic patients (130 men, 47 women) from Toronto and Central Canada. All patients were diagnosed on the basis of the Structured Clinical Interview for DSM-IV Axis I/Patients (SCID-I/P) (APA, 1994), and each subject gave a 30-ml blood sample for DNA extraction. All subjects gave written informed consent. In addition, a medication history questionnaire was administered to each patient, in which current tobacco consumption was also addressed. If the subjects identified themselves as a smoker, then further questions determined the number of cigarettes per day. If the subject was currently a nonsmoker, no other question were asked regarding previous smoking behavior including whether or not they had quit smoking. Thus, quitters would be classified as nonsmokers. Based on the questionnaire responses, 108 (85 men, 23 women) were identified as 'current smokers', while 69 (43 men, 26 women) were classified as 'current nonsmokers'. In all, $93 \%$ of the smokers and $91 \%$ of the nonsmokers were of Caucasian ethnicity (Table 1). The nonsmokers fraction in our sample is $38 \%$ a number higher than the reported $15 \%$ of hospitalized schizophrenics; however, our sample consists of mostly outpatients who are less prone to smoke (Uzun et al, 2003).

All subjects were unrelated, with the exception of two sib pairs that were included in the study. The smokers $v s$

Table I Demographic Difference between Two Groups

\begin{tabular}{lcc}
\hline & Smokers & Nonsmokers \\
\hline Sample size & 108 & 69 \\
Male & $87(81 \%)$ & 43 \\
Female (\%) & $21(19 \%)$ & $26(38 \%)$ \\
Age & $41.0 \pm 10.7$ & $38.2 \pm 10.9$ \\
Caucasian \% & $93 \%$ & $91 \%$ \\
\hline
\end{tabular}

Age reliability $t=-1.678 ; 174 \mathrm{df}, p=0.09$; gender ratio reliability $\chi^{2}=5.96, \mathrm{Idf}$, $p=0.01$ nonsmokers were group matched for ethnicity and age to reduce the potential effect of population stratification.

We genotyped the D15S1360 dinucleotide polymorphism in the $\alpha 7$ nicotinic receptor gene (CHRNA7), as described in Freedman et al (1997), using the ABI 3100 (Applied Biosystem, Foster City, CA). Gault et al (1998) described the structural organization of the CHRNA7 gene as being partially duplicated; however, the locus D15S1360 appears to be unique in the genome, and therefore provides genotypes easier to interpret than markers in the duplicated region. The genotype data were analyzed using $\chi^{2}$ test and logistic regression.

\section{RESULTS}

The D15S1360 marker exhibited seven different dinucleotide repeat lengths $(99,109,111,113,115,117$, and $125 \mathrm{bp})$, with a heterozygosity of $43 \%$ (calculated as number of heterozygous subjects in the total sample). Two major alleles, 113 and $115 \mathrm{bp}$, accounted for nearly $90 \%$ of the alleles. This finding is quite similar to that reported by Freedman et al (1997), although they did not find the very rare alleles. We tested whether the empirically derived genotype frequencies were in Hardy-Weinberg equilibrium at D15S1360 using the public domain program HWE by Ott (1999). Theoretically, there should be 28 individual genotypes composed of all the possible combinations of the seven observed alleles; however, only 12 different genotypes were represented in our sample population. The D15S1360 marker exhibited no deviation from Hardy-Weinberg equilibrium $\left(\chi^{2}=11.14,21 \mathrm{df}, p=0.95\right)$. These individuals were divided into four groups according to the genotype they possessed, that is, 113/113,113/115, 115/115, and others (mixed groups). In spite of previous reports in literature (Stassen et al, 2000), we found highly significant differences $\left(\chi^{2}=10.37,3 \mathrm{df}, p=0.015\right)$ between the allele distributions of smokers and nonsmokers among schizophrenia patients. The genotype counts for this polymorphism were significantly different between the two groups $\left(\chi^{2}=10.39,3 \mathrm{df}, p=0.01\right)$ (Table 2). The estimated OR was 1.60 (95\% CI 1.04-2.46), $p=0.04$. Ethnicity and age did not contribute to the differences between the two groups $\left(\chi^{2}=0.04,1 \mathrm{df}, p=0.84 ; t=-1.678,175 \mathrm{df}, p=0.09\right)$ (Table 1). The largest contribution to the $\chi^{2}$ was from the 113 and $115 \mathrm{bp}$ alleles. Among smokers, the allelic frequencies were $53.7 \%$ for the $113 \mathrm{bp}$ allele and $40.2 \%$ for the $115 \mathrm{bp}$ allele compared to nonsmokers, where the frequencies were 42 and $46.3 \%$, respectively. Power calculation revealed that, if the frequency of exposure is approximately $60 \%$, our sample has a power $>80 \%$, with $\alpha=0.05$, to detect a genotype relative risk $<2$ (Risch, 2000).

The two groups were matched for age and ethnicity. The analysis of genotype and allelic distributions across the two ethnic groups demonstrates that this marker did not show ethnic stratification: $\chi^{2}=5.59,3 \mathrm{df}, p=0.13$ and $\chi^{2}=4.02$, $2 \mathrm{df}, p=0.13$, respectively. Our Caucasian population is mainly from Western Europe, and there are no major differences in the distribution of ethnicities between smokers and nonsmokers. Furthermore, to our knowledge, there are no reports that have found any differences in allelic distribution of D15S1360 across Caucasian samples. 
Table 2 DI5SI360 Differences in Smokers/Nonsmokers

\begin{tabular}{|c|c|c|}
\hline Allele $^{a}$ & Smokers & Nonsmokers \\
\hline Sample size & 216 & 138 \\
\hline 113 bp (\%) & I 16 (53.7\%) & $58(42.0 \%)$ \\
\hline II 5 bp (\%) & 87 (40.2\%) & 64 (46.3\%) \\
\hline III bp (\%) & 5 & 12 \\
\hline Others (\%) & 8 & 4 \\
\hline \multicolumn{3}{|l|}{ Genotype } \\
\hline $113 / 113$ & 38 (36\%) & II (16\%) \\
\hline $113 / 115$ & 32 (29\%) & 28 (4I\%) \\
\hline $115 / 115$ & $25(23 \%)$ & 15 (22\%) \\
\hline Others & $13(12 \%)$ & I5 (22\%) \\
\hline
\end{tabular}

${ }^{a}$ Allele counts include rarer genotypes not specified in the genotype table.

Table 3 DI5SI360 Female Differences

Genotype Female smokers $(n=2 I)$ Female nonsmokers $(n=26)$

\begin{tabular}{llr}
\hline $113 / 113$ & $6(28 \%)$ & $4(15 \%)$ \\
$113 / 115$ & $7(33 \%)$ & $7(27 \%)$ \\
$115 / 115$ & $8(39 \%)$ & $5(19 \%)$ \\
Others & $0(0 \%)$ & $10(39 \%)$
\end{tabular}

\begin{tabular}{lcc} 
Allele $^{\mathbf{a}}$ & Smokers $(\boldsymbol{n}=\mathbf{4 2})$ & Nonsmokers $(\boldsymbol{n}=\mathbf{5 2})$ \\
\hline I I3 bp & $19(45 \%)$ & $20(38 \%)$ \\
I I $5 \mathrm{bp}$ & $23(55 \%)$ & $21(40 \%)$ \\
Others & $0(0 \%)$ & $11(22 \%)$ \\
\hline
\end{tabular}

Genotype: $\chi^{2}=10.68,3 \mathrm{df}, p=0.0$ 1; allele: $\chi^{2}=10.17,2 \mathrm{df}, p=0.006$.

${ }^{a}$ Allele counts include rarer genotypes not specified in the genotype table.

However, there were significant sex differences $\left(\chi^{2}=5.96\right.$, $1 \mathrm{df}, p=0.01)$. There were more males in among the smokers than nonsmokers (81 vs 62\%) (Table 1). A logistic regression analysis incorporating genotype and sex showed a significant interaction between $113 \mathrm{bp}$ (homozygous + heterozygous) allele and males with an estimated OR of 1.85 (95\% CI 1.01-3.41), $p=0.04$. The association between D15S1360 and smoking was analyzed separately in males and females. There were significant differences observed between female smokers and nonsmokers (genotype: $\chi^{2}=10.68,3 \mathrm{df}, p=0.01$; allele: $\chi^{2}=19.17,2 \mathrm{df}, p=0.006$ ) (Table 3). For males, smoking was significantly associated with genotype: $\chi^{2}=7.74,3 \mathrm{df}, p=0.05$ (Table 4), with a trend towards an association between smoking and the 113-bp allele $\left(\chi^{2}=4.18,2 \mathrm{df}, p=0.12\right)$ (Table 4$)$.

\section{DISCUSSION}

Our results demonstrate a significant genetic difference between schizophrenia patients who smoke and those who do not. Our data need to be replicated in an independent sample population, and the genotyping of additional genetic markers would also further inform our
Table 4 DI5SI360 Male Differences

\begin{tabular}{|c|c|c|}
\hline Genotype & Smokers $(n=87)$ & Nonsmokers $(n=43)$ \\
\hline $113 / 113$ & 32 (37\%) & $7(16 \%)$ \\
\hline $113 / 115$ & $25(29 \%)$ & $21(49 \%)$ \\
\hline $115 / 115$ & $17(19 \%)$ & $10(23 \%)$ \\
\hline Others & $13(15 \%)$ & $5(12 \%)$ \\
\hline Allele $^{a}$ & Smokers $(n=174)$ & Nonsmokers $(n=86)$ \\
\hline $113 b p$ & $96(55 \%)$ & $38(42 \%)$ \\
\hline 115 bp & $64(37 \%)$ & $43(50 \%)$ \\
\hline Others & $14(8 \%)$ & $5(8 \%)$ \\
\hline
\end{tabular}

Genotype: $\chi^{2}=7.74,3 \mathrm{df}, p=0.05$; allele: $\chi^{2}=4.18,2 \mathrm{df}, p=0.12$.

${ }^{a}$ Allele counts include rarer genotypes not specified in the genotype table.

results. The association between the 113-bp allele of the D15S1360 marker in the CHRNA7 gene and smoking may be related to the clinical observation that patients with schizophrenia are more likely to smoke and to smoke heavily. Schizophrenia is characterized by well-documented cognitive and neurophysiological deficits, including abnormal p50 auditory evoked potentials, which are mediated in part by the CHRNA7 receptor. Previous reports have shown a link between the D15S1360 marker in the CHRNA7 receptor gene and P50 (Freedman et al, 1997). The most salient question that arises from these results is whether the neurobiology of schizophrenia makes patients more vulnerable to nicotine addiction, and/or whether nicotine improves the cognitive or sensory-gating deficits. The finding of a greater genetic effect in women is interesting, as social convention protects them from heavy smoking to some extent. We did not study healthy control subjects, but one previous report comparing the CHRNA7 genotypes of healthy smokers and nonsmokers did not show significant differences (Stassen et al, 2000).

The increased proportion of the D15S1360 risk allele $113 \mathrm{bp}$ in schizophrenic patients who smoke (especially in male smokers) suggests that smoking among schizophrenia patients may be mediated more by the addiction to nicotine. This hypothesis is further supported by a series of studies: smokers with schizophrenia are more likely to have had an earlier age of onset of schizophrenia, to have had a greater number of hospitalizations, to display significant reduction in Parkinsonism, to have more akathisia, and to have a higher total score on the BPRS (Goff et al, 1992).

The mechanism by which the D15S1360 marker may have an effect on smoking in schizophrenia is unclear and requires further experimental work; however, it is possible that the alleles of the D15S1360 marker confer different characteristics of mRNA stability and/or processing. It is also possible that $113 \mathrm{bp}$ allele at this marker cosegregates with a nearby functional site that may affect the function of this receptor in schizophrenia. However, among the new variants found by Gault et al (2003), the closest one is located at least $30 \mathrm{~kb}$ from D15S1360 and with a minor allele frequency lower than $3 \%$. Thus, it is unlikely to be informative, and unlikely to be in strong linkage disequilibrium with the $113 \mathrm{bp}$ allele. 
The definition of smoking status is not entirely consistent for subjects reported in the literature on CHRNA7 and $P 50$, and this makes direct comparisons between studies difficult. Nevertheless, our data indicate that there are greater differences between smokers and nonsmokers among schizophrenics than among healthy control subjects (Stassen et al, 2000). The Stassen et al study was exclusively based on data derived from a relatively small number of smokers within a control group recruited to match with patients with psychiatric disorders, and was not in HardyWeinberg equilibrium. Our sample was in Hardy-Weinberg equilibrium, suggesting that population stratification was not a factor in our results.

One possible limitation to this study is the fact that some of our current nonsmokers may have been smokers and quit at some time in the past; thus, for future studies, examinations such as the Fagerstron Questionnaire (Heatherton et al, 1991) are warranted. We believe that this number of subjects will be fairly small, since these patients have multiple behavioral and cognitive impairments, quitting smoking may be very difficult for them (Ziedonis et al, 1994); furthermore, the lack of smoking cessation interventions for schizophrenics can explain the fact that these patients have less access to smoking cessation programs than the normal population (Addington et al, 1997). Addington et al (1998) have noted that schizophrenia patients have difficulty in complying with smoking cessation programs, and when they do complete the program, only $12 \%$ are successful at remaining abstinent at 6 months follow-up.

Despite the limitations, including a small sample size of the samples studied, our study suggests a role of the D15S1360 polymorphism in pathogenesis of nicotine addiction in patients with schizophrenia. Further investigations are needed in larger independent samples to confirm this factor in the complex mechanisms of heavy smoking in schizophrenics.

In summary, our findings suggest an association between a polymorphism in the CHRNA7 receptor gene and smoking status in schizophrenia. This may be relevant to the neurobiology of nicotine addiction, to the cognitive deficits seen in schizophrenia, or to the treatment of schizophrenia. The data may also represent a distinction between schizophrenic smokers and nonsmokers that could represent an endophenotype, suitable for further genetic studies.

\section{ACKNOWLEDGEMENTS}

We acknowledge Nicole King and Sajid Shaikh for their assistance in the laboratory procedure.

\section{REFERENCES}

Addington J, el-Guebaly N, Campbell W, Hodgins DC, Addington D (1998). Smoking cessation treatment for patients with schizophrenia. Am J Psychiatry 155: 974-976.

Addington J, el-Guebaly N, Addington D, Hodgins D (1997). Readiness to stop smoking in schizophrenia. Can J Psychiatry 42: 49-52.

Adler LE, Hoffer LD, Wiser A, Freedman R (1993). Normalization of auditory physiology by cigarette smoking in schizophrenic patients. Am J Psychiatry 150: 1856-1861.
Adler LE, Hoffer LJ, Griffith J, Waldo MC, Freedman R (1992). Normalization by nicotine of deficient auditory sensory gating in the relatives of schizophrenics. Biol Psychiatry 32: 607-616.

Adler LE, Olincy A, Waldo MC, Harris JG, Griffith J, Stevens K et al (1998). Schizophrenia, sensory gating, and nicotinic receptors. Schiz Bull 24: 189-202.

American Psychiatric Association (APA) (1994). Diagnostic and Statistical Manual of Mental Disorder (DSM-IV). 4th edn. American Psychiatric Press: Washington, DC. pp 282.

Court J, Spurden D, Lloyd S, McKeith I, Ballard C, Cairns N et al (1999). Neuronal nicotinic receptors in dementia with Lewy bodies and schizophrenia: alpha-bungarotoxin and nicotine binding in the thalamus. J Neurochem 73: 1590-1597.

de Leon J, Dadvand M, Canuso C, White AO, Stanilla JK, Simpson GM (1995). Schizophrenia and smoking: an epidemiological survey in a state hospital. Am J Psychiatry 152: 453-455.

Freedman R, Adler LE, Bickford P, Byerley W, Coon H, Cullum CM et al (1994). Schizophrenia and nicotinic receptor. Harvard Rev Psychiatry 2: 179-192.

Freedman R, Coon H, Myles-Worsley M, Orr-Urtreger A, Olincy A, Davis A et al (1997). Linkage of a neurophysiological defict in schizophrenia to chromosome 15 locus. Proc Natl Acad Sci USA 94: 587-592.

Freedman R, Hall M, Adler LE, Leonard S (1995). Evidence in postmortem brain tissue for decreased numbers of hippocampal nicotinic receptors in schizophrenia. Biol Psychiatry 38: 22-33.

Gault J, Hopkins J, Berger R, Drebing C, Logel J, Walton C et al (2003). Comparison of polymorphisms in the alpha7 nicotinic receptor gene and its partial duplication in schizophrenic and control subjects. Am J Med Genet (Neuropsychiatric Genet) 123: 39-49.

Gault J, Robinson M, Berger R, Drebing C, Logel J, Hopkins J et al (1998). Genomic organization and partial duplication of the human alpha7 neuronal nicotinic acetylcholine receptor gene (CHRNA7). Genomics 52: 173-185.

Goff DC, Henderson DC, Amico E (1992). Cigarette smoking in schizophrenia: relationship to psychopathology and medication side effects. Am J Psychiatry 149: 1189-1194.

Heatherton TF, Kozlowki LT, Frecker RC, Fagerstrom KO (1991). The Fagerstrom test for nicotine dependance: a revision of the Fagerstrom tolerance questionnaire. Br J Addict 86: 1119-1127.

Kauffman CA, Suarez B, Malaspina D, Pepple J, Svrakic D, Markel $\mathrm{PD}$ et al (1998). NIMH genetics initiative millennium schizophrenia consortium: linkage analysis of African-American pedigrees. Am J Med Genet (Neuropsychiatric Genet) 81: 282-289.

Leonard S, Adams C, Breese CR, Adler LE, Bickford P, Byerley W et al (1996). Nicotinic receptor function in schizophrenia. Schiz Bull 22: 431-445.

Leonard S, Bertrand D (2001). Neuronal nicotinic receptors: from structure to function. Nic Tob Res 3: 203-223.

Leonard S, Gault J, Moore T, Hopkins J, Robinson M, Olincy A et al (1998). Further investigation of a chromosome 15 locus in schizophrenia: analysis of affected sibpairs from the NIMH genetics initiative. Am J Med Genet (Neuropsychiatric Genet) 81: 308-312.

Leonard S, Gault J, Moore T, Hopkins J, Robinson M, Olincy A et al (2002). Promoter variants in the alpha7 nicotinic acetylcholine receptor subunit gene are associated with inhibitory deficit found in schizophrenia. Arch Gen Psych 59: 1085-1096.

Lindstrom J, Anand R, Peng X, Gerzanich V, Wang F, Li Y (1996). Neuronal nicotinic receptor subtypes. Ann NY Acad Sci 757: $100-116$.

Luntz-Leybhan V, Bickford PC, Freedman R (1992). Cholinergic gating of response to auditory stimuli in rat hippocampus. Brain Res 587: 130-136.

Ott J (1999). Analysis of Human Genetic Linkage. 3rd edn. John Hopkins University Press: Baltimore.

Risch NJ (2000). Searching for genetic determinants in the new millennium. Nature 405: 847-856. 
Stassen HH, Bridler R, Hägele S, Hergersberg S, Mehmann B, Schinzel A et al (2000). Schizophrenia and smoking: evidence for a common neurobiological basis? Am J Med Genet (Neuropsychiatric Genet) 96: 173-177.

Stevens KE, Freedman R, Collins AC, Hall M, Leonard S, Marks JM et al (1996). Genetic correlation of inhibitory gating of hippocampal auditory evoked response and alpha-bungarotoxin-binding nicotinic cholinergic receptors in inbred mouse strains. Neuropsychopharmacology 15: 152-162.

Stevens KE, Kem WR, Mahnir VM, Freedman R (1998). Selective alpha7-nicotinic agonists normalize inhibition of

auditory response in DBA mice. Psychopharmacology 136: 320-327.

Uzun O, Canserver A, Basoglu C, Ozsahin A (2003). Smoking and substance abuse in outpatients with schizophrenia: a 2-year follow-up study in Turkey. Drug Alchohol Depend 70: 187-192.

Zhang ZW, Vijayaraghavan S, Berg DK (1994). Neuronal acetylcholine receptors that bind alpha-bungarotoxin with high affinity function as ligand-gated ion channels. Neuron 12: 167-177.

Ziedonis DM, Kosten TR, Glazer WM, Frances RJ (1994). Nicotine dependence and schizophrenia. Hospital Community Psychiatry 45: 204-206. 